\title{
ALFREDO PANZINI
}

UMI PERFIL

\section{Luigi Castagnola \\ Universidade do Paraná}

Ao apresentar seu livro de nobres perfis, cheios de vivas recordações, Bento Munhoz da Rocha Netto escrevia sob o impulso da emoção evocadora: "Êles se foram, como todos. Mas permanecem" (1). E o ilustre paranaense dizia também porque permaneciam aquelas nobres figuras por êle evocadas com: tanta saudade: deixaram elas um sulco de luz na sociedade em que viveram.

Ao traçar o perfil de Alfredo Panzini, no ano centenário de seu nascimento, poderíamos começar com as mesmas palavras: Elle se foi. Como todos. Mas permanece. E permanece porque deixou um sulco de luz na sociedade em que viveu, construiu seu destino com energia incansável, durante cinqüenta anos dedicados às letras italianas e quarenta consagrados ao magistério.

Panzini foi um literato que se realizou a si mesmo porque quis, e quis porque sabia de ter em si mesmo as fôrças e as qualidades para ser alguém na história da literatura italiana. Não é raro o caso, em tôdas as literaturas, de alguém alcançar logo a notoriedade graças aos amigos, que dispensam elogios em tôda a imprensa, e aos criticos benévolos, que acham e louvam a arte literária mesmo onde ela não existe.

Nāo é êste o caso de Panzini.

Com efeito, êle encaminhou-se sòzinho para a montanha áspera e angustiosa da arte e da poesia, e teve que andar longas jornadas antes de encontrar o sorriso e a aprovação de algum confrade. A simpatia do público bafejou-o sòmente depois de longos esforços e numerosas publicações. Contam que 
o editor Emílio Treves disse um dia a Panzini, seu colaborador na Illustrazione Italiana: "Mas sabe que é estranho? Eu continuo publicando as suas novelas porque gosto delas, mas ninguém se apercebe de que o senhor é um escritor".

Nem por isso desanimou Panzini ou teve a menor dúvida a respeito de sua vocação literária. Não se queixou de seu momentâneo infortúnio, não se atirou contra os críticos, nem se abandonou a estéreis lamúrias e inúteis melancolias. Mais tarde, quando todo o mundo, quase de repente, viu em Panzini uma das vozes líricas mais originais das letras italianas da primeira metade dêste século, o escritor não mudou seu estilo de vida e de artista, nem se envaideceu. Continuou seu caminho como antes, trabalhando, lecionando, escrevendo, como se a glória e a fama o tivessem bafejado desde sempre. Os críticos se penitenciaram hábil e apressadamente, e o público foi ler também os livros que Panzini havia publicado desde anos.

A Itália celebra, neste ano (*), também o primeiro centerário de nascimento de um outro famoso escritor, Gabriele D'Annunzio. Certamente, a parte maior dos elogios e dos festejos caberá a D'Annunzio, que, sob muitos aspectos, foi todo o contrário de Panzini. D'Annunzio foi poeta e soldado, herói da primeira guerra mundial, conquistador e governador de Fiume, comandante e príncipe de Monte Nevoso; viveu no fausto, conheceu o destêrro desdenhoso, a volta triunfal à pátria, os aplausos das multidões; abandonou a Universidade de Roma para ir ao encontro da glória poética e literária, tornando-se famoso ainda muito môço; seu mundo é o mundo dos deuses antigos e dos heróis, do super-homem, dos mitos, dos acontecimentos extraordinários e lendários; nunca foi professor e fêz saber que não aceitaria nem sequer a cátedra de literatura na Universidade de Bolonha, quando pensavam em lha oferecer, e terminou sua vida presidente da Academia da Itália, morrendo no majestoso parque do Vittoriale, às margens do lago de Garda.

Nada disso encontramos na vida de Alfredo Panzini. Fêz êle um curso regular de estudos, formando-se pela Universida-

(*) Este artigo fol escrito em 1963, para comemorar o primelro centenário do nascimento de A. Panzinl. 
de de Bolonha e, logo depois, foi lecionar a vida tôda nos ginásios da Itália; seu trato foi garbosamente senhoril, um tanto independente e orgulhoso, mas nunca aparatoso e principesco, nem foi à guerra para ser um herói. Viveu, fantàsticamente, no mundo dos antigos poetas clássicos, e, quando acabava o estafante ano letivo, gostava de viajar por todos os recantos da Itália de trem ou em bicicleta, ou então descansar na sua modesta casa de Bellária, em face do mar Adriático. Uma vida, portanto, simples e um tanto rotineira, bem diversa da de D'Annunzio.

No entanto, se D'Annunzio, do Parnaso das Musas, se dignasse olhar para a Itália de hoje, não lhe seria difícil ver que a sua fama não é mais "sonorosa" como outrora, e os literatos seus contemporâneos lhe arrabataram o primeiro lugar em todos os gêneros literários por êle tentados. De fato, o seu rival Luigi Pirandello é, incontestàvelmente, maior novelista e dramaturgo do que êle; Mastro don Gesualdo e $I$ Malavoglia de Giovanni Verga, e o Piccolo mondo antico de Antônio Fogazzaro são romances artisticamente superiores aos de D'Annunzio, conforme o juízo unânime da critica literária; e no céu da poesia italiana a estrêla de Giovanni Páscoli é mais brilhante do que a de D'Annunzio.

Não diremos que Panzini seja maior artista do que D'Annunzio, pois essa afirmação, pela novidade contrária à tradição, seria considerada uma heresia literária. Mas um leitor de bom gôsto, na atualidade, após ter lido todo D'Annunzio e todo Panzini, muito provàvelmente acabará achando mais simpática e agradável a companhia do segundo. Literatos e críticos italianos já salientaram que o herói de ontem não empolga mais as novas gerações; citaremos apenas dois autores de grande autoridade para confirmar o que dissemos: Giovanni Titta Rosa e Giuseppe Ravegnani.

Titta Rosa, em artigo publicado no Osservatore politico $e$ letterario, escreve que, um século após o nascimento de D'Annunzio, o poeta parece hoje "come un grande edificio solcato da crepe insanabili" (2). Giuseppe Ravegnani, em seus I Contemporanei, assim fala de D'Annunzio:

"In questi ultimi perigliosi anni, la posizione della critica dinanzi all'arte inimitabile di Gabriele 
d'Annunzio, avendo assunto un tono di lode assai più guardinga, schifiltosa e spesso addirittura fastidita, ci appare, in certo modo, alterata al confronto di quanto, ai tempi dell'Alcyone o del Fuoco, essa significava... Il tempo, a poco a poco, ha levato gl'impacci; appartenendo D'Annunzio, più che alla vita letteraria, alla storia... Il distacco di Gabriele D'Annunzio dai giovani e dalle nuove generazioni si fa sempre più profondo e aspro... Non uno che voglia prenderselo come maestro, oggi... Le nuove generazioni s'allontanano sempre più dal D'Annunzio fatale. Il suo attivismo di vita, profuso in un'arte essenzialmente immaginosa e parolaia, è tanto superumano da risultare sterile, dinanzi alla coscienza d'un popolo" (3).

Mas voltemos a Panzini, pois é dêle que devemos aqui falar, cem anos após seu nascimento.

A trajetoria de sua vida corporal, digamos assim, se apresenta, como acima salientamos, bastante simples e quase rotineira.

Os pais de Panzini moravam em Rímini, mas o escritor nasceu na última hora do último dia de 1863, em Senigállia, na região das Marcas, na casa do avô materno, aonde a mãe, Filomena Santini, fôra passar breve temporada. Brincando, Panzini dizia que se lembrava de Senigállia sòmente quando devia escrever, nos documentos oficiais, também o lugar de seu nascimento. Fêz seus primeiros estudos em Rímini, onde o pai exercia a profissão de médico. Aos dez anos de idade, os pais conseguiram matriculá-lo e interná-lo no Colégio Nacional Marco Foscarini, em Veneza. Na cidade das lagunas cursou o ginásio e o liceu, destacando-se pela diligente aplicação aos estudos literários e queimando, ao sair do colégio, todos os livros de matemática.

Panzini escreveu certa vez: "O mundo é grande e, para a maioria, também feliz; oferece certamente largo e vivaz campo à atividade de um jovem: mas eu, educado por muitos anos em um numeroso colégio, havia-me convencido de que, saindo da porta do colégio, não tinha outra coisa a fazer senão enfiarm-me pela porta de uma universidade! 
Mas estudar para professor, isto absolutamente não!"

De sua vida de colégio Panzini falou muitas vêzes em seus escritos, dando a impressão de detestar os anos que passou engaiolado no Marco Foscarini. Em suas Memorie di scuola, entretanto, fala com grande simpatia e saudade de seu professor de filosofia, Giorgio Politeo, um homem de grande personalidade, que sabia infundir nos alunos a educação cristã e a cultura clássica.

"Era di nazione dalmata, e nell'aspetto, quasi povero, recava una lindura e una purità vigorosa da ricordade i più classici tipi anglo-sassoni. Ma il suo pensiero, pur essendo spoglio di verbosità e di rioriture retoriche, era squisitamente latino, cioè umano... Nutriva verso noi giovani quella benevolenza costante e serena che è il primo requisito per chi insegna e che invano si spera di poter apprendere nelle scuole di pedagogia, si che, porgendo insieme l'immagine di un vero impèrio morale, costringeva i giovani a disciplinato contegno... Io non saprei ben ridire a quale scuola filosofica egli appartenesse; ma ci pareva che andasse poco d'accordo con tutti gli altri filosofi delle scuole... Pochi professori furono come lui così mediocri svolgitori di programmi: ma era un allevatore di anime, e ogni suo studio pareva fosse rivolto a questo fine: condurre la mente del giovane a pensare da sè, a muoversi antonoma $e$ non per effetto di un rimorchio".

Panzini deve certamente a êsse professor de liceu a inclinação à ironia e a tendência a moralizar, que encontramos tão freqüentemente em suas obras.

Acabado o curso colegial, ou liceal, como costumam dizer na Itália, Panzini matriculou-se na Universidade de Bolonha, onde foram seus mestres sempre admirados, Giosuè Carducci, Francesco Acri e Giovanni Battista Gandino. Do tempo passado na Universidade de Bolonha Panzini guardou por tôda a vida saudosa recordação, e dedicou muitas páginas de suas obras à evocação daqueles anos acadêmicos e às nobres figuras de seus grandes mestres. 
Carducci era então um professor e um poeta famoso na. Itália, e exercia uma fascinação imensa sôbre a mocidade culta e estudiosa; Panzini não escapou a essa fascinação e a visão de Carducci, mestre e poeta, nunca mais se apagou na memória e no espírito de jovem universitário.

"Chi, tra i frequentatori della facoltà di lettere a Bologna, non ricorda il caratteristico entrare del Carducci nella scuola di filologia?...

Alcuni scolari, ad un suo cenno, andavano a prendere i soliti testi di consultazione: egli passava dall'uno all'altro scolaro; rivedeva i quaderni, i libri, gli appunti. Erano per noi momenti terribili.

"A lei!" questa era la parola sacramentale.

L'interpellato cominciava e leggeva. A poco a poco la scuola si animava e ripigliava il solito aspetto...

Il suo metodo didattico è ammirevole e perfetto. L'interrogato legge e chiosa; ne' passi controversi od oscuri ognuno è libero di esporre la sua interpretazione. Egli ascolta, accetta, disapprova, corregge, talvolta loda, in fine amplifica e fornisce tutti gli elementi per cui il giudizio si possa accostare al vero; e se alcuna cosa ignora in quella sua molteplice ricerca, lo confessa liberamente; ne prende appunto per sé ed invita altri ad approfondire la questione...

Un'altra cosa a cui teneva moltissimo era appunto quella a cui nelle scuole, per quanto mi sappia, si tiene pochissimo, cioè leggere, nient'altro che leggere. Durante le lezioni di magistero, saliva su per i banchi, si metteva lì, vicino a uno scolaro con un: - Legga lei. - E poi stava a sentire come un maestro di musica ascolta l'armonia degl'istrumenti".

Além dos acadêmicos, iam ouvir as aulas de Carducci muitas outras pessoas amantes da cultura. Foi assim que Panzini conheceu um dia o imperador do Brasil, Dom Pedro II. 
"Una volta lo (Carducci) vidi guardare uno che era entrato e aveva deposto, entrando, un gran cappello di feltro grigio. Era una testa barbata e di gran dignità. Si stava seduto in un banco vicino a noi, ma composto e silenzioso.

Il Maestro, appena lo vide, corse a lui, e i due uomini si abbracciarono.

Era don Pedro, l'imperatore del Brasile".

Também Francesco Acri, profundo conhecedor de Platão e espírito sinceramente católico, influiu muito sôbre Panzini, despertando nêle a tendência ao filosofar.

"Francesco Acri - escreve Panzini - che veniva dalle terre della Magna Grecia, era nostro professore di filosofia in Bologna, ed era uomo spiritualissimo in mezzo all'imperversare delle dottrine materialiste, che allora andavano sfacciatamente nude, cioè non coperte dei veli ingannevoli dell'idealismo. Aveva egli per usanza - al cominciar della primavera - di dare convegno a noi scolari sul bel colle dell'Osservanza in su le prime ore del mattino. (Chi avesse voluto venire, s'intende). E lì, con quella sua voce ondulata di pause penetranti e sapienti, leggeva Platone e lo faceva leggere a noi; ma così, bonariamente, senza la noia della filologia che a quei tempi era gran signora nelle scuole; bensì come viaggio straordinario per i mari inesplorabili del pensiero.

Fiori e sole erano intorno, giovinezza nei cuori. Si sceglieva un luogo all'ombria, e ognuno si posava come meglio piaceva intorno al buon maestro, si che un pittore ne avrebbe composto un quadro come quelli delle antiche scuole, senza scolari legati ai banchi.

Poi salendo il sole verso l'ora del mercato pieno - come dicevano i greci - egli ci dava commiato e se ne ritornava tutto solo alla città; e noi, o indimenticabile memoria! andavamo a far colazione". 
Em 1886, Panzini se formava em letras pela Universidade de Bolonha. Um ano antes, havia falecido o pai do escritor, deixando a família em difíceis condições financeiras, devido à sua falta de capacidade administrativa e ao jôgo. Panzini começou logo a lecionar, em 1886, no ginásio de Castellamare di Stábia, perto de Nápoles. No ano seguinte, foi transferido para Imola e, em 1888, para Milão, onde ficou até 1917. Na capital da Lombardia, Panzini lecionou no curso ginasial do Liceu Parini, até 1912, depois no Instituto Técnico e, contemporâneamente, desde 1897, no Politécnico e, a partir de 1901, no Círculo Filológico.

Em 1890, casou-se; dêsse casamento nasceram-lhe alguns filhos.

Gostava de passar suas férias à beira-mar, em Bellária, onde construiu uma residência em 1906. Amava muito aquêle recanto sossegado e pitoresco; quando já velho, aposentado e Acadêmico da Itália, aí passava grande parte do ano.

Após regular concurso, em 1917, foi lecionar em Roma, no instituto técnico Leonardo da Vinci até 1924, e depois no liceu Terenzio Mamiani até 1927. Naquele ano, após quarenta anos de ensino, pediu a aposentadoria, que conseguiu a partir de janeiro de 1928. Não quis nenhuma festa de despedida.

"L'ultima volta che si allontanò dalla sua scuola per non tornarvi più — escreve Mormino - uscì al solito dal portone col suo passo lento e sostenuto, solenne nell'alta statura e nelle sue spalle quadrate; il consueto bastone in mano al quale non ha bisogno di appoggiarsi. A piedi rifece la strada verso casa, come tutti i giorni. Vedendolo si sarebbe detto: Ecco il professor Panzini che, terminata la lezione, se ne va a desinare".

Em março de 1929, ingressava na Academia da Itália. Dez anos mais tarde falecia em Roma (1939), e quis ser sepultado no pequeno cemitério de Canônica, não distante de Bellária.

Como se vê, simples, rotineira e trabalhosa foi a vida dêste escritor, que conquistou um lugar importante na literatura italiana da primeira metade dêste século, graças aos seus méritos incontestáveis. 
A partir de 1911, se tornou largamente conhecido e elogiado pela crítica; mas não bajulou ninguém para conquistar fama. Não se filiou a nenhuma escola poética, nem se rodeou de amigos com o objetivo de ser elogiado. Percorreu seu caminho quase solitário; podia dizer de si mesmo, como Giovanni Páscoli:

Ascesi il monte senza lo strepito delle compagne grida...

Da me, da solo, solo con l'anima, con la piccozza d'acciar ceruleo, su lento, su anelo, su sempre; spezzandoti, o gelo!

Teve que publicar muito antes de conquistar a simpatia dos leitores, mas não se queixou demasiadamente por esta falta de sorte, e aceitou outrossim com serena energia a dura vida do trabalho que o destino lhe havia reservado. Desde môço, êle pensava que cada qual, inclusive o escritor, é o artífice de sua fortuna; ninguém devia mendigar o êxito, ou recorrer ao auxílio do estado. Num seu escrito de 1907, Panzini lamenta que nos corredores do colégio onde havia estudado, em Veneza, não tivessem escrito máximas pedagógicas do tipo americano, como, por exemplo, a seguinte: "Rapazes! o mundo é grande. Cuidai de ganhar o pão de todos os dias por vossa conta! O estado não é pròpriamente um asilo, nem um refeitório".

Como professor, Panzini foi incansável e nunca se abandonou à mediocridade e à rotina, como acontecia a muitos seus colegas. Na sua longa carreira profissional, conheceu êle certamente tôdas as angústias do professor, mas, no fundo, gostava de lidar com os alunos. Num dos seus primeiros contos, põe na bôca de um professor de ginásio estas palavias, que poderiam ser dêle mesmo:

"Cominciai a trovarmici bene in mezzo a quegli scolaretti. Ve n'erano alcuni così graziosi, cosi buoni, che era uno svago viverci in mezzo. Spiegavo la grammatica, correggevo i loro latini, facevo delle lunghe prediche di morale e di civile virtù desunte dai classici, e lo debbo dire? le ore mi fuggivano 
quivi più riposatamente che altrove, tanto che io stesso demandavo al direttore di fermarmi una qualche mezz'oretta di più".

Começou a escrever em 1890 e publicou mais de sessenta volumes. Mencionaremos aqui os mais representativos.

Il libro dei Morti (1893);

L'evoluzione di Giosuè Carducci (1894);

Gli ingenui (1896);

Moglie nuova (1899);

Il 1859: Da Plombières a Villafranca (1900);

Piccole storie del mondo grande (1901);

Lepida et Tristia (1902);

Trionfi di donna (1903);

Dizionario moderno (1905);

La lanterna di Diogene (1907);

Le fiabe della virtù (1911);

Novelle d'ambo $i$ sessi (1911);

Santippe (1914);

La Madonna di Mamà (1916);

Viaggio di un povero letterato (1919);

Io cerco moglie (1920);

Il diavolo nella mia libreria (1921);

Il padrone sono me (1922);

La pulcella senza pulcellaggio (1924);

La vera storia dei tre colori (1924);

I tre re con Gelsomino buffone del re (1927);

Il mondo è rotondo (1928);

I giorni del sole e del grano (1929);

La sventurata Irminda (1931);

Avventure di Signora Nostra Parola (1933);

Novelline divertenti per bambini intelligenti (1935);

Il ritorno di Bertoldo (1936);

Il bacio di Lesbia (1937);

Além disso, Panzini publicou ainda cinco antologias para 
as escolas, e foi assíduo colaborador de Il Corriere della Sera, o famoso jornal de Milão, da Nuova Antologia e da Illustrazione Italiana.

A prosa de Panzini é elegante, clássica e pura, embora não tivesse êle mêdo de recorrer a neologismos com bastante liberdade, quando achava que assim devia fazer.

Croce the reconheceu o dom da poesia; Papini via nêle um escritor simpático e agradável. A partir de 1911, como dissemos, a crítica literária considerou unânimemente Panzini como um dos mais cristalinos prosadores da Itália. Ranieri Allulli e Piero Nardi apresentaram ao público italiano duas antologias panzinianas: Pagine dell'alba e La mia storia il mio mondo. Giuseppe Mormino (4) e Gabriele Baldini (5) dedicaram a Panzini dois volumes preciosos e ricos de notícias biográficas e de apreciações literárias.

Também Panzini teve seu drama espiritual e foi um espírito sofredor. Idealista por natureza, compreendeu bem cedo, porém, que o mundo não é tão cheio de heróicos cavalheiros e de heroínas belas e imaculadas, como se lê nos livros dos poetas. Pelo contrário, o mundo pareceu-lhe muitas vêzes cheio de trapaceiros e malandros egoistas, que pretendem passar por homens honestos e bem comportados. Ao fazer a mesma descoberta, Leopardi abandonou-se ao desalento e ao desespêro melancólico, Carducci reagiu como uma fera, atirando suas flechadas furibundas contra todo o mundo. A atitude de Panzini é diferente. Não se abandonou ao melancólico desespêro, como Leopardi, nem esbofeteou o mundo, como Carducci. Il mondo è rotondo, diz o título de um livro de Panzini; os homens de hoje são como os homens de ontem, e a sociedade de amanhã não será diversa da de hoje. Será sempre assim. Mas Panzini

"... non si abbandona e non capitola di fronte alla vita; i ricordi ed i sogni lo consolano e la coscienza della sua superiorità morale lo sorregge; ma egli non sa sdegnarsi e non vuol giudicare. L'indignazione gli sembra cosa vana ed antiquata: una sorella della retorica. Il giudizio, che in questo caso sarebbe condanna, dovrebbe fondarsi su principi indiscussi, 
su verità assolute in cui egli non crede, poichè lo studio e la riflessione gli hanno insegnato a dubitarne: perciò osserva, scruta, analizza, ricorda; poi scuote il capo e sorride. Tale è la vita; cosifatto è l'uomo; su questi binari si muove la storia, ora come nel passato; e allora a che giova inveire, imprecare, invocare? (6).

Diante da miséria espiritual da humanidade, Panzini não se tornou um espírito negador, um cético indiferente; a realidade pareceu-lhe demais complicada e contraditória, por isso suas análises não chegam a nenhuma síntese definitiva; mas, no fundo, estava convencido de que devemos ficar fiéis aos princípios da honestidade. Panzini não sabe dizer com clareza porque devemos ficar fiéis à honestidade, pois a luz da fé religiosa não iluminava a alma do escritor. Havia recebido uma educação cristã na sua infância, e a nobre grandeza de uma vida cristã havia êle admirado nos seus professôres Politeo e Acri; mas ao longo de sua existência aquela chama se havia apagado, embora dela guardasse no coração uma profunda saudade, alimentada pelas recordações da mãe, que amou sempre de modo terno e afetuoso, e de cujos sentimentos profundamente religiosos não raro fala em suas obras com grande respeito.

"Quante volte nel dolce mese di maggio io giunsi in quella città (Rimini, onde morava a mãe do escritor), e bussai alla porta della casa! la mamma non c'era in casa; e donne del vicinato dicevano che era andata alla chiesa: la ritrovavo in chiesa, lì presso, col capo chiuso nel suo nero scialle... Forse è lì che la ritroverò ancora! . . E quando io verrò a te, tu forse mi verrai incontro sul limitare e mi chiamerai per nome e mi dirai ancora: Benvenuto!"

Alfredo Panzini se foi, como todos. Mas permanece. E permanece para nos dizer com sua longa existência, dedicada à arte e ao trabalho, que a vida deve ser empregada nalguma coisa útil e nobre, desfraldando a bandeira da esperança. $\mathbf{E}$ porque permanece o evocamos neste ano centenário de seu nascimento. 


\section{NOTAS}

1) BENTO MUNHOZ DA ROCHA NETTO, Perfis, Curitiba, 1960, p. 5.

2) Cf. L'Osservatore politico e letterario, Milano, $1963, \mathrm{n} .{ }^{\circ} 3$.

3) Giuseppe RAVEGNANI, I Contemporanei, Milano, Ceschina, vol. I, 1960, pp. 45-47.

4) Giuseppe MORMINO, Alfredo Panzini nelle opere e nella vita, Milano, Albrighi e Segati, 1927.

5) Gabriele BALDINI, Panzini, Brescia, Morcelliana, 1941.

6) Alfredo GALLETTI, Il Novecento, Milano, Vallardi, 1951, pp. 376377. 